\title{
Facial nerve palsy: an unusual feature of Plasmodium falciparum
}

\author{
Clifford Onuorah Okike ${ }^{1 *}$, Chinonyelum Thecla Ezeonu², Benson Nnamdi Onyire ${ }^{2}$ and Pius Chukwuka Manyike ${ }^{2}$ \\ *Correspondence: cliffordokike@yahoo.com \\ ${ }^{1}$ Federal Medical Centre, Asaba, Nigeria. \\ ${ }^{2}$ Federal Teaching Hospital, Abakaliki, Nigeria.
}

\begin{abstract}
A ten-year old boy who presented with headache, intermittent high grade fever for four days and left sided deviation of the mouth two days later. Examination revealed a fully conscious patient with an axillary temperature of $39.5^{\circ} \mathrm{C}$ and right facial nerve palsy, lower motor neuron lesion. No other obvious abnormality was detected in any of the systems. Laboratory examination showed positive Plasmodium falciparum (P. falciparum) with a density of 28,000 parasites $/ \mathrm{mm}^{3}$. Cranial computerized tomographic scan and abdominal ultra-sonograghy revealed no abnormality. Cerebrospinal fluid (CSF) analysis showed normal cell count and chemistry. Culture yielded no growth. Retroviral screening test was negative. Complete blood count showed high monocytosis of $18 \%$, other indexes were normal. Electrolytes, urea, creatinine and calcium levels were within normal limits. Urine, stool and blood cultures yielded no growth. Random blood sugar (RBS) and liver function test were normal. Symptoms subsided within 36 hours following administration of intravenous artesunate and oral paracetamol. Complete facial nerve recovery took seven days following clearance of parasitemia. The objective of this report is to draw the attention of clinicians to this uncommon presentation of malaria, though the patho-physiological mechanism remains unclear.
\end{abstract}

Keywords: Malaria, facial nerve, federal medical centre

\section{Background}

Malaria is the most important tropical parasitic disease affecting about 247 million people each year among the 3.3 billion people at risk, resulting in nearly a million deaths, mostly children under the age of five years [1]. Nearly $90 \%$ of these deaths occur in Africa, South of the Sahara thereby making it the leading cause of under-five mortality, killing an African child every 30 seconds [2]. In Nigeria, malaria remains a major public health problem, responsible for $60 \%$ outpatient visits to health facilities, $25 \%$ infant death and $11 \%$ maternal death [3]. Childhood malaria continues to be a major cause of morbidity and mortality with attendant rising cost of treatment, loss of productivity and earning due to days lost from illness $[4,5]$.

Literatures on $P$. falciparum as a cause of seventh cranial nerve palsy are scanty. The commonest cause of facial nerve paralysis is Bell's palsy. In this condition no specific cause can be ascertained. The diagnosis is therefore made having excluded reasonable possible causes [6]. Recovery of facial paralysis due to Bell's palsy begins within three weeks of onset of the illness with complete recovery occurring within three to six months [7]. Sim et al., [8] reported facial diplegia in a 20 year old boy infected with Plasmodium vivax in Korea while Duque et al., [9] reported bilateral $6^{\text {th }}$ cranial nerve palsy caused by $P$. falciparum in a 14 year old Caucasian living in Democratic Republic of Congo. Haematological response to malaria infection has been documented. Robert et al., [10] documented that monocyte count was higher in children diagnosed of malaria in comparison to non-malaria infected children. Similarly, Halim et al., [11] reported high monocyte count among sixty five children with positive malaria parasitemia. Other causes of facial nerve palsy include herpes zoster infection affecting facial nerve in the facial canal of the mastoid bone [12]. Evidence of this disease include facial nerve palsy associated with vesicular rash in or behind the ear [12]. Diabetes mellitus, chronic suppurative otitis media, meningitis, mumps parotitis, human immunodeficiency virus and intracranial space occupying lesions are also known causes of facial nerve palsy.

To the best of the authors' knowledge, facial nerve paralysis resulting from $P$. falciparum infection has not been documented in Nigeria. This report therefore aims at alerting clinicians especially those working in malaria endemic areas on this rare and unusual manifestation of malaria and also to add to the body of knowledge.

\section{Case report}

This is a case of a ten-year old boy who presented at the outpatient clinic of Federal Medical Centre, Asaba, Nigeria with a four-day history of severe headache and high grade intermittent fever. Two days later, parents noticed that his mouth was deviated to the left. There was no antecedent head injury, no convulsion, no altered sensorium nor features of respiratory tract infection. There was no history of acute or chronic ear discharge, no rash in or behind the ear, no associated speech or hearing impairment and patient is not a known diabetic. There was no history of vomiting or diarrhoea. His pre-morbid state was normal. Clinical examination revealed a fully conscious patient with axillary temperature of $39.5^{\circ} \mathrm{C}$ and blood pressure of $90 / 50 \mathrm{mmHg}$. Right sided facial nerve palsy, lower motor neuron lesion was noted. There were no signs of meningeal irritation; power and tone in all the limbs was normal. Examination of the 
Okike et al. Paediatrics and Health 2013,

http://www.hoajonline.com/journals/pdf/2052-935X-1-1.pdf

doi: $10.7243 / 2052-935 X-1-1$

ears, nose and throat showed no abnormality. Cardiovascular and respiratory systems were normal. The liver, spleen and kidneys were not palpably enlarged. Malaria parasite test was positive with a density of 28,000 parasites $/ \mathrm{mm}^{3}$ of asexual form of $P$. falciparum. Cranial computerised tomographic scan, abdomino-pelvic ultrasonography and chest x-ray revealed no abnormality. CSF analysis showed glucose level of $2.8 \mathrm{mMol} / \mathrm{L}$ (normal; $2.1-4 \mathrm{mMol} / \mathrm{L}$ ) and protein of $0.2 \mathrm{~g} / \mathrm{L}$ (normal; $0.1-0.4 \mathrm{~g} / \mathrm{L}$ ). The CSF cell count was $1 \mathrm{WBC} / \mathrm{mm}^{3}$. Complete blood count showed total white blood cell count of $6.6 \times 10^{9} /$ L(normal; 4.0-10.0 $10 \%$ L), nuetrophil, 41\%(normal; 40-65\%), lymphocytes,39\% (normal; $25-35 \%$ ), eosinophil, $2 \%$ (normal; $0-7 \%$ ), monocyte, $18 \%$ (normal; 2-6\%), packed cell volume, $40 \%(36-45 \%)$. Random blood sugar was $96 \mathrm{mg} / \mathrm{dl}$ (normal; $70-$ $120 \mathrm{mg} / \mathrm{dl})$. Liver function test showed total bilirubin of $6 \mu \mathrm{Mol} /$ $\mathrm{L}($ normal; $5-17 \mu \mathrm{Mol} / \mathrm{L})$, aspartate transaminase of $3 \mathrm{IU} / \mathrm{L}(0-12$ $\mathrm{IU} / \mathrm{L}$ ), alanine transaminase of $3.2 \mathrm{IU} / \mathrm{L}$ (normal; $0-12 \mathrm{IU} / \mathrm{L}$ ) and alkaline phosphatase of $22.7 \mathrm{IU} / \mathrm{L}$ (normal; 20-28 IU/L). Serum electrolytes urea and creatinine values were within normal range; sodium $138 \mathrm{mMol} / \mathrm{L}$ (normal, $135-145 \mathrm{mmol} / \mathrm{L}$ ), potassium $3.7 \mathrm{mMol} / \mathrm{L}$ (normal; $3.5-5 \mathrm{mMol} / \mathrm{L}$ ), urea $3.1 \mathrm{mMol} / \mathrm{L}$ (normal; $2.5-6.8 \mathrm{mMol} / \mathrm{L}$ ), creatinine $12 \mu \mathrm{Mol} / \mathrm{L}$ (normal; $9-124 \mu \mathrm{Mol} / \mathrm{L}$ ), bicarbonate $26 \mathrm{mMol} / \mathrm{L}$ (normal; $24-30 \mathrm{mMol} / \mathrm{L}$ ) and calcium $2.4 \mathrm{mMol} / \mathrm{L}$ (normal; 2.24-2.75). Urine, stool and blood cultures yielded no growth. Retroviral screening was negative. Viral serology for herpes infection was not done because there were no clinical features of such infection and technology for such viral study was not available in the medical centre. He was admitted and treated with oral paracetamol and intravenous artesunate. Symptoms of fever and headache subsided within 36 hours but complete recovery of the facial nerve took seven days following clearance of parasitemia. Neither steroid nor antibiotics was administered to the patient as urine, stool, blood and CSF cultures yielded no bacterial growth.

\section{Discussion}

The mechanism underlying facial nerve palsy in malaria caused by Plasmodium falciparum is unclear. It has been postulated that malaria parasite may damage the peripheral nerves by vascular occlusion, thus causing anoxic stagnation in the vasa nervosum, which may lead to temporary demyelination and recovery after disappearance of the parasitemia and establishment of normal blood flow in the vasa nervosum [8]. In malaria, asexual-stage infections are accompanied by the release of cytokines and other immunological mediators that may mimic Guillain-Barre syndrome $[9,13]$.It is likely that these immunological mediators may have caused demyelination in the index patient giving rise to Gullain-Barre like syndrome affecting only the facial nerve. However no serologic test was done for the purpose of isolating antibodies against neuronal tissues because the facility for this investigation was not available in the centre where this patient was managed. It may also be due to local effect of the parasites on the facial nerve since the paralysis is the lower motor neuron type. This assertion is subject to future studies to determine vulnerable areas of the facial nerve that can be affected by P. falciparum. It may be argued that this patient may have suffered from Bell's palsy. But Bell's palsy is a disease condition in which no specific cause can be ascertained [6]. Additionally, complete resolution of paralysis in Bell's palsy occurs within six months to one year which is a sharp contrast to the index patient whose facial paralysis resolved within seven days following complete parasite clearance. Meningitis, diabetes mellitus and intra-cranial lesions were reasonably excluded. CSF culture and analysis, CT scan and RBS showed no abnormal features. Herpes zoster affectation of the $7^{\text {th }}$ cranial nerve within the mastoid bone is a common cause of facial palsy. But this is usually associated with vesicular rash behind or in the ear. The index patient had no evidence of such rash clinically, though viral serology would have been useful to completely rule out the infection. The only evidence of the cause of fever and facial nerve paralysis in this patient is $P$. falciparum parasitemia of $28,000 / \mathrm{mm}^{3}$. Additionally, studies have shown that monocytosis is a common association with acute malaria infection $[10,11]$ This index patient had high level of monocytes count indicative of anti-malarial effect of monocytes.

\section{Conclusion}

We therefore conclude that though this one case of facial nerve palsy associated with Plasmodium falciparum infection may not be enough to draw relevant conclusion, clinicians practicing in malarial endemic areas should be stimulated to watch out for this rare and unusual manifestation of malaria especially in the West African sub region where $P$. falciparum is endemic.

\section{Competing interests}

The authors declare that they have no competing interests.

\section{Authors' contributions}

Okike CO conceived and designed the research, acquired, analyzed and interpreted data, drafted the manuscript and made critical review of the manuscript. Ezeonu CT participated in acquisition and analysis of data. She also contributed immensely to the draft and critical review of the manuscript. Onyire BN helped in the interpretation of all laboratory results, supplied relevant literatures and critically reviewed the drafted manuscript. Manyike PC joined Onyire in laboratory result analysis and interpretation. He also contributed to critical revision of the manuscript.

\section{Acknowledgment}

The authors acknowledge the support of the paediatric resident doctors during the management of this patient. The effort of Adorah Okike is appreciated for finding time to type the manuscript.

\section{Publication history}

Received: 15-Apr-2013 Revised: 12-May-2013

Accepted: 23-May-2013 Published: 27-May-2013 
Okike et al. Paediatrics and Health 2013,

\section{References}

1. World Health Organization. WHO malaria report 2008. WHO/HTM/ GMP/2008.1. I Website

2. Word Health Organization. Making every mother and child count - The Word Health Organization Report, 2005. | Website

3. Federal Ministry of Health, Nigeria. National malaria control programme. (cited August 11, 2012). I Website

4. Abdulahi K, Abubakar U, Adamu T, Dareji Al, Aliyu RU, Jiya N, Ibrahim MTO, Nata'ala SU: Malaria in Sokoto, North West Nigeria. Afr J Biotech 2009, 7:101-05. | Article

5. Agu AP, Nwojiji JO: Childhood malaria : mothers' perception and treatment-seeking behavior in a community in Ebonyi State, South East Nigeria. J Community Med Prim Healthcare 2005, 17:45-50. | Article

6. Morris AM, Deeks SL, Hill MD, Midroni G, Goldstein WC, Mazzulli T, Davidson R, Squires SG, Marrie T, McGeer A and Low DE: Annualized incidence and spectrum of illness from an outbreak investigation of Bell's palsy. Neuroepidemiology 2002, 21:255-61. | Article | PubMed

7. Peitersen $\mathrm{E}$ : The natural history of Bell's palsy. Am J Otol 1982, 4:107-11. I PubMed

8. Sim JE, Choi YC and Kim WJ: Facial Diplegia in Plasmodium vivax Malaria. J Clin Neurol 2010, 6:102-3. | Article | PubMed Abstract | PubMed Full Text

9. Duque V, Seixas D, Ventura C, Da Cunha S and Melico-Silvestre A: Plasmodium falciparum malaria, bilateral sixth cranial nerve palsy and delayed cerebellar ataxia. J Infect Dev Ctries 2012, 6:290-4. | Article | PubMed

10. Maina RN, Walsh D, Gaddy C, Hongo G, Waitumbi J, Otieno L, Jones D and Ogutu BR: Impact of Plasmodium falciparum infection on haematological parameters in children living in Western Kenya. Malar J 2010, 9 Suppl 3:S4. | Article | PubMed Abstract | PubMed Full Text

11. Halim NKD, Ajayi O, Oluwafemi F: Monocytosis in acute malaria infection. Nig J Clin Pract 2002, 5:106-108. | Article

12. Holland NJ and Weiner GM: Recent developments in Bell's palsy. BMJ 2004, 329:553-7. | Article | PubMed Abstract | PubMed Full Text

13. Wijesundere A: Guillain-Barre syndrome in Plasmodium falciparum malaria. Postgrad Med J 1992, 68:376-7. | Article | PubMed Abstract | PubMed Full Text

Citation:

Okike CO, Ezeonu CT, Onyire BN and Manyike PC: Facial nerve palsy: an unusual feature of Plasmodium falciparum. Paediatrics and Health 2013, 1:1.

http://dx.doi.org/10.7243/2052-935X-1-1 